Check for updates

Cite this: J. Mater. Chem. C, 2021, 9, 4948

Received 17th January 2021,

Accepted 14th March 2021

DOI: 10.1039/d1tc00223f

rsc.li/materials-c

\title{
The local atomic structure and thermoelectric properties of Ir-doped ZnO: hybrid DFT calculations and XAS experiments $\dagger$
}

\author{
Andrei Chesnokov, (D) a Denis Gryaznov, (D) *a Natalia V. Skorodumova, bc \\ Eugene A. Kotomin, ${ }^{\text {ad }}$ Andrea Zitolo, (D) ${ }^{e}$ Martins Zubkins, (D) ${ }^{a}$ Alexei Kuzmin, (D) ${ }^{a}$ \\ Andris Anspoks $\mathbb{D D}^{a}$ and Juris Purans ${ }^{a}$
}

\begin{abstract}
We combined the hybrid density functional theory (DFT) calculations and X-ray absorption spectroscopy (XAS) experiments in the study of the local atomic structure around Ir ions in ZnO thin films with different iridium content. This was then used in the first principles analysis of the thermoelectric properties of material. The emphasis has been put on the conditions for a positive Seebeck coefficient and p-type electrical conductivity as the functions of the Fermi level. We studied both computationally and experimentally several possible $\mathrm{IrO}_{x}$ polyhedra (complexes) with a different number of surrounding oxygens and Ir oxidation states, including those with the formation of peroxide ions $\left(\mathrm{O}_{2}^{2-}\right)$. In particular, octahedral coordination of iridium ions was identified by reverse Monte Carlo (RMC) simulations of the Ir $\mathrm{L}_{3}$-edge EXAFS spectra of $\mathrm{ZnO}$ :Ir thin films as the predominant complex, which is supported by the calculated lowest interstitial oxygen incorporation energies. All the calculated $\operatorname{IrO}_{x}(x=4,5,6)$ complexes, regardless of Ir the oxidation state, demonstrate potential for $p$-type conduction if the Fermi level $\left(\mu_{\mathrm{F}}\right)$ falls in the range of $0-0.8 \mathrm{eV}$ from the valence band maximum (VBM) and the Ir concentration is high enough $(12.5 \%$ in the present DFT calculations). Even though the corresponding calculated Seebeck coefficient $(S)$ around 80-89 $\mu \mathrm{V} \mathrm{K}^{-1}$ slightly exceeds the experimental values, we emphasise the presence of an important plateau in the dependence of $S$ on $\mu_{\mathrm{F}}$ in this range for two complexes with the formation of peroxide ions $\left(\mathrm{O}_{2}{ }^{2-}\right)$. We predicted also that peroxide ions $\mathrm{O}_{2}{ }^{2-}$ are characterized by the calculated phonon frequencies of $810-942 \mathrm{~cm}^{-1}$ in agreement with our previous Raman experimental results. In this light, we discuss the high sensitivity of calculated $S\left(\mu_{\mathrm{F}}\right)$ dependences to the atomic and electronic structure.
\end{abstract}

\section{Introduction}

Zinc oxide $(\mathrm{ZnO})$ is widely used in semiconductor and optoelectronic industries. Despite more than two decades of intensive research, the capabilities of $\mathrm{ZnO}$ are still not exhausted. It can be grown as large bulk single crystals of high quality,

\footnotetext{
${ }^{a}$ Institute of Solid State Physics, University of Latvia, Kengaraga 8, Riga, LV-1063, Latvia. E-mail: gryaznov@mail.com

${ }^{b}$ Department of Materials Science and Engineering, School of Industrial Engineering and Management, KTH-Royal Institute of Technology, Brinellvägen 23, Stockholm, Sweden

${ }^{c}$ Department of Physics and Astronomy, Uppsala University, Box 516 75120 Uppsala, Sweden

${ }^{d}$ Max Planck Institute for Solid State Research, Heisenbergstr. 1, Stuttgart, D-70569, Germany

${ }^{e}$ Synchrotron SOLEIL, L'orme des Merisiers, BP 48 Saint Aubin, 91192 Gif-sur-Yvette, France

† Electronic supplementary information (ESI) available. See DOI: 10.1039/ d1tc00223f
}

deposited as thin films, or made amorphous. ${ }^{1-3}$ It has a $3.4 \mathrm{eV}$ wide band gap, strong luminescence, high electron mobility, high thermal conductivity and large exciton binding energy. Due to these properties, $\mathrm{ZnO}$ is regarded as a promising material for a wide variety of applications, including but not limited to transparent conductors, sensors/emitters of blue and UV light, and to functional coatings. ${ }^{4,5}$ In particular, modern electronics requires stable p-type thin films with sufficiently high transparency and p-type conductivity. Modified ZnO can be a stable n-type conductor, and the current research focuses on achieving stable p-type conductivity. Concurrently, as a result of advances in growing methods, the research scope is also shifting towards an amorphous phase of $\mathrm{ZnO}^{6}$

To date, there has been room for more details on a study of the behaviour of intrinsic and impurity defects in ZnO. A comprehensive analysis of intrinsic defect behaviour by using advanced optical measurements was recently performed for defect-rich single $\mathrm{ZnO}^{7}$ crystals. In the interpretation of 
photo-luminescence spectra the oxygen vacancies $\left(\mathrm{V}_{\mathrm{O}}\right)$, the vacancy pairs $\left(\mathrm{V}_{\mathrm{O}}-\mathrm{V}_{\mathrm{Zn}}\right)$, $\mathrm{Zn}$ interstitials and their complexes were identified. In $\mathrm{ZnO}$ electronic donors are formed spontaneously leading to intrinsic doping asymmetry. ${ }^{8}$ Even though the oxygen vacancy possesses the lowest formation energy under $\mathrm{Zn}$ and O-rich conditions in most theoretical studies on bulk material, understanding conditions for the growth of the thin films plays a very important role. The literature indicates that the analysis of defects in thin films should be done with caution. For instance, the Mn-doped $\mathrm{ZnO}$ thin films required theoretical computations to explain discrepancies in the interpretation of XANES (X-ray absorption near edge structure) spectra. ${ }^{9}$ It was established that neither $\mathrm{O}$ nor $\mathrm{Zn}$ vacancies are detectable in the XANES spectra. Their presence is less important than local structure changes induced by the Mn impurity. The present study focuses on the d-electron impurity, Ir. ZnO:cIr thin films ( $c$ is the Ir concentration) have demonstrated the change in the sign of the Seebeck coefficient from negative to positive for Ir concentration ranging from $c=12.4$ to $16.4 \% .{ }^{10}$ High oxygen partial pressure during the $\mathrm{ZnO}: c \mathrm{Ir}$ thin film deposition and film transformation into the amorphous phase with the Ir concentration $c=7-16 \%$ at room temperature allows us to suggest an important role of oxygen interstitials $\left(\mathrm{O}_{\mathrm{i}}{ }^{\prime} \mathrm{s}\right) .{ }^{10}$ However, atomistic understanding of the changes in the ZnO:cIr thin film properties was missing. Notice that the present experiments considered a wider range of Ir concentrations and were mainly focused on the local atomic structure around Ir. Raman spectroscopy results revealed ${ }^{10}$ the existence of a vibrational band at $720 \mathrm{~cm}^{-1}$, and it was argued that its presence is not due to the $\mathrm{IrO}_{2}$ phase but is rather related to the formation of a peroxide moiety $\left(\mathrm{O}_{2}{ }^{2-}\right)$. The existing body of work ${ }^{5}$ relating to $\mathrm{ZnO}$ largely agrees on the fact that $\mathrm{O}_{\mathrm{i}}$ tends to form an $\mathrm{O}-\mathrm{O}$ 'dumbbell' or 'split interstitial'. This may show both donor- and acceptor-like qualities as discussed based on DFT calculations. ${ }^{11}$

Notice that previous DFT calculations of Ir-doped ZnO did not discuss the thermoelectric properties and the effect of Seebeck coefficient sign change. ${ }^{12-14}$ Thus, the present DFT calculations address these peculiar properties of $\mathrm{ZnO}$ :Ir thin films and explore the connection between the role of Ir impurity and $\mathrm{O}_{\mathrm{i}}$ for the electronic structure, thermoelectrical properties and p-type conduction. We use several models of $\mathrm{IrO}_{x}$ polyhedra (called, hereafter, $\mathrm{IrO}_{x}$ complexes) in $\mathrm{ZnO}$, distinguished by the number of oxygens surrounding Ir, the oxidation state of $\mathrm{Ir}$, incorporation energy of $\mathrm{O}_{\mathrm{i}}$ 's and the presence of peroxide defects. Thus, we can find interpretations in the Seebeck coefficient dependences on $\mu_{\mathrm{F}}$ for potential p-type conduction in Ir-doped ZnO.

The experimental section describes details of preparing Ir-doped $\mathrm{ZnO}$ and pure $\mathrm{IrO}_{x}$ thin films and synchrotron radiation XAS measurements at the $\mathrm{Ir}_{\mathrm{L}_{3}}$-edge. Subsequent sections on methods introduce the models for the calculation of $\operatorname{IrO}_{x}$ complexes in $\mathrm{ZnO}$ and present computational details, including those regarding the thermoelectric properties. The results section is divided into several subsections to discuss the results of the extended X-ray absorption fine structure (EXAFS) spectra analysis using reverse Monte Carlo (RMC) simulations, the calculated structural properties of $\mathrm{IrO}_{x}$ complexes in $\mathrm{ZnO}$ and those of the parent compounds, the electronic structure properties of $\mathrm{IrO}_{x}$ complexes in $\mathrm{ZnO}$, and the main results of thermoelectric property calculations.

\section{Methods}

\section{Experimental}

Mixed zinc-iridium oxide (ZnO:cIr) and pure $\mathrm{IrO}_{x}$ amorphous thin films were deposited on polyimide tape substrates at room temperature by reactive DC magnetron co-sputtering in an $\mathrm{Ar}$ $(20 \mathrm{sccm})+\mathrm{O}_{2}(10 \mathrm{sccm})$ atmosphere $(10 \mathrm{mTorr}$ working pressure). A metallic Zn (99.95 wt\%) target with Ir (99.6 wt\%) pieces placed on the target erosion zone were used for sputtering. The thin film thickness was about $200-300 \mathrm{~nm}$. The iridium concentration ( $c=7 \%, 16 \%, 29 \%, 54 \%$ and $67 \%$ ) was determined using X-ray fluorescence measurements. X-ray diffraction measurements confirm the amorphous structure of all films. More details about the experimental procedure can be found in ref. 10 .

X-ray absorption spectra (XAS) at the $\mathrm{Ir}_{\mathrm{L}_{3}}$-edge were measured at room temperature at the SAMBA bending-magnet beamline ${ }^{15}$ of the Synchrotron SOLEIL storage ring. The experiments were performed in transmission mode using the focusing $\mathrm{Si}(220)$ monochromator and two ionization chambers. For each sample, a multi-layered sandwich was prepared to obtain a sufficiently large total thickness of samples with an absorption edge jump close to 1 . The processing of XAS was performed using a conventional procedure, ${ }^{9}$ as implemented in the XAESA code. $^{16}$

The Ir $\mathrm{L}_{3}$-edge EXAFS spectra in mixed zinc-iridium oxide (ZnO:cIr) and pure $\operatorname{IrO}_{x}$ thin films were analysed using the reverse Monte Carlo (RMC) method ${ }^{17}$ based on the evolutionary algorithm (EA), which is implemented in the EvAX code. ${ }^{18}$

\section{DFT calculations}

We have performed all DFT calculations using the Crystal17 v 1.0.2 $2^{19-22}$ computer code. We used the supercell approach, ${ }^{23}$ and as such we have modelled defective structures of $\mathrm{ZnO}$ (wurtzite structure with four atoms per unit cell, space group $\mathrm{P6}_{3} \mathrm{mc}$ ) using $2 \times 2 \times 1$ (i.e. four times extended unit cell L4, consisting of 16 atoms) or $4 \times 4 \times 3$ (L48, 192 atoms) supercells. These supercells represented 12.5 (L4) and 1.04 (L48) atomic \% concentrations of Ir. In all cases, Ir ion substituted a regular $\mathrm{Zn}$ ion. In the following analysis, we refer to this defect as the $\operatorname{Ir}^{n} \mathrm{O}_{x}$ complex, where $n$ denotes the oxidation state ${ }^{24}$ and $x$ is the number of oxygen ions adjacent to Ir. In the wurtzite structure, $\mathrm{Zn}$ has four nearest $\mathrm{O}$ ions. Thus, we first model Ir surrounded by four host oxygen ions. In the results section we will show that $n=2+$ in this case, i.e. $\operatorname{Ir}^{2+} \mathrm{O}_{4}$. Other complexes included the $\mathrm{O}_{\mathrm{i}}$ ions. In our calculations we considered numerous atomic configurations and used the incorporation energy of $\mathrm{O}_{\mathrm{i}}$ 's (discussed below) to choose the most important ones. There is a different complex with four oxygen ions surrounding 
Ir but with $n=3+$, i.e. $\operatorname{~Ir}^{3+} \mathrm{O}_{4}$, due to only one $\mathrm{O}_{\mathrm{i}}$ adjacent to $\mathrm{Ir}$ and simultaneously forming $\mathrm{O}_{2}{ }^{2-}$ with a host oxygen (our first complex with the formation of $\mathrm{O}_{2}{ }^{2-}$ ). There is the complex with five oxygen ions surrounding $\mathrm{Ir}$ with $n=4+$, i.e. $\operatorname{Ir}^{4+} \mathrm{O}_{5}$, due to two $\mathrm{O}_{\mathrm{i}}$ 's close to Ir. In this complex one of the $\mathrm{O}_{\mathrm{i}}$ ions forms $\mathrm{O}_{2}{ }^{2-}$ with the host oxygen (our second complex with the formation of $\mathrm{O}_{2}{ }^{2-}$ ). Lastly, there is the complex with six oxygen ions surrounding Ir with $n=4+$, i.e. $\mathrm{Ir}^{4+} \mathrm{O}_{6}$, due to two $\mathrm{O}_{\mathrm{i}}$ 's close to Ir and without formation of $\mathrm{O}_{2}{ }^{2-}$. The atomic structure of each complex after the full structure relaxation can be seen in Fig. 5 and in Fig. S1 (ESI $\dagger$ ).

We analyse the oxidation state $n$ of $\operatorname{Ir}^{n} \mathrm{O}_{x}$ in the different complexes by comparing it to reference materials: $\mathrm{IrO}_{2}$ (formal oxidation state of iridium is $4+$ ), a hypothetical $\mathrm{Ir}_{2} \mathrm{O}_{3}$ (formal oxidation state $3+$ ), and to $\mathrm{ZnIr}_{2} \mathrm{O}_{4}$ (formal oxidation state $3+$ ). All these materials were modelled in their common reported structures: tetragonal (space group $P 4_{2} / m n$, rutile structure) for $\mathrm{IrO}_{2}$, rhombohedral (space group $R \overline{3} c$, corundum structure) for $\operatorname{Ir}_{2} \mathrm{O}_{3}$, and cubic (space group $\mathrm{Fd} \overline{3} \mathrm{~m}$, spinel structure) for $\mathrm{ZnIr}_{2} \mathrm{O}_{4}$. To the best of our knowledge, the preparation of single-crystal $\mathrm{Ir}_{2} \mathrm{O}_{3}$ is not yet reported. However, its presence in $\mathrm{IrO}_{2}$ powders was discussed in ref. 25 and 26, and corundum $\operatorname{Ir}_{2} \mathrm{O}_{3}(001)$ surface oxide was synthesized at high oxygen pressure $^{27}$ in the oxidation of the $\operatorname{Ir}(111)$ surface. Besides, several papers describe and report measurements of properties of devices based on corundum-structured $\operatorname{Ir}_{2} \mathrm{O}_{3}$, although without discussing the actual structure of the material. ${ }^{28,29}$

Our DFT calculations are based on the method of linear combination of atomic orbitals (LCAO). We use atom-centered basis sets (BS) of Gaussian-type functions adopted from the literature. The relativistic effective core pseudopotential with 60 core electrons $^{30}$ and basis set of triple-zeta valence with f-polarization function ${ }^{30,31}$ for Ir were taken from the Basis Set Exchange resource ${ }^{32}$ and used earlier by Ping et al. ${ }^{33}$ All-electron BSs for $\mathrm{O}$ and $\mathrm{Zn}$ were taken from ref. 33 and Gryaznov et al. ${ }^{34}$ respectively. We modified the basis set for $\mathrm{Zn}$ by optimizing exponent values of the two most diffuse orbitals: one from the sp series and one from the d series (see the ESI $\dagger$ for details). We optimized these values with respect to the total electronic energy of the system with constant volume and atomic positions. The convergence limit of this procedure, based on the Powell's conjugate direction method and used as implemented in the OPTBAS ${ }^{35}$ interface to CRYSTAL, was set to $10^{-5}$ a.u. For all other calculations, the convergence limit on the total energy for the self-consistent field procedure was set to $10^{-7}$ a.u. for both electronic and lattice structure relaxation.

As the exchange-correlation functional we chose a hybrid PBE0 functional with $25 \%$ of Hartree-Fock exchange. ${ }^{36}$ We should mention that the bandgap value of pure $\mathrm{ZnO}$ obtained in the present calculations with the PBE0 functional is $3.45 \mathrm{eV}$, a value that is reasonably close to the experimental value of $3.44 \mathrm{eV}^{37}$ and which did not require an increase of the amount of exact exchange suggested in the literature for the HSE functional. $^{38}$ Indeed, our test calculation with the HSE functional showed a band gap of $2.93 \mathrm{eV}$, suggesting that this effect is basis-independent. The Brillouin zone was sampled with either $4 \times 4 \times 4$ (for the L4 supercell) or a $2 \times 2 \times 2$ (L48) $\Gamma$-centered $k$-point mesh generated with the Monkhorst-Pack ${ }^{39}$ method. All calculations of defective structures in the neutral supercells were spin-polarized and did not include the spinorbit effects; the use of symmetry operations was explicitly omitted. Computational parameters (the choice of basis sets, functional and integration precision) have been validated to faithfully represent the bulk properties of $\mathrm{ZnO}, \mathrm{IrO}_{2}$ and $\mathrm{Ir}_{2} \mathrm{O}_{3}$, and $\mathrm{ZnIr}_{2} \mathrm{O}_{4}$.

\section{$\mathrm{O}_{\mathrm{i}}$ incorporation energy}

As discussed above, the $\mathrm{IrO}_{x}$ complexes with $n$ exceeding $2+$ are not obtainable in the wurtzite structure by simply substituting $\mathrm{Zn}$ with Ir. The number of oxygen neighbours for each cation in the wurtzite structure is 4 . Therefore, the additional $\mathrm{O}_{\mathrm{i}}$ atoms are required. Thus, in our calculations for the $\mathrm{Ir}^{3+} \mathrm{O}_{4}$, $\mathrm{Ir}^{4+} \mathrm{O}_{5}$ and $\mathrm{Ir}^{4+} \mathrm{O}_{6}$ complexes defective L4 supercells contain 18 ions (8 metals and 10 oxygens) meaning two $\mathrm{O}_{\mathrm{i}}$ 's were added. The large supercell L48, containing 194 ions (96 metals and 98 oxygens) was used for the $\mathrm{Ir}^{4+} \mathrm{O}_{6}$ only. Optimization of atomic positions in a defective supercell may lead to very different atomic configurations; therefore, energetic criteria are important for their comparison. To compare systems of different atomic configurations we use the so-called incorporation energy, calculated from total electronic energies:

$$
E_{\text {inc }}\left(\mathrm{O}_{\mathrm{i}}\right)=E\left(\mathrm{O}_{\mathrm{i}}\right)-E(\mathrm{Ir})-E\left(\mathrm{O}_{2}\right),
$$

where $E\left(\mathrm{O}_{\mathrm{i}}\right)$ is the total electronic energy of the supercell with two $\mathrm{O}_{\mathrm{i}}$ atoms and with an Ir atom, $E(\mathrm{Ir})$ is the total electronic energy of the supercell with $\operatorname{Ir}^{2+} \mathrm{O}_{4}$ and without $\mathrm{O}_{\mathrm{i}}$, and $E\left(\mathrm{O}_{2}\right)$ is the total electronic energy of an oxygen molecule. The incorporation energies were successfully introduced to analyze the stability of fission products at different pre-existing trap sites in $\mathrm{UO}_{2}{ }^{40}$ Pre-existing trap sites may include vacancies and interstitials. In the case of interstitial sites, the incorporation energy coincides with the solution energies being different by the formation energy of the trap site. A negative value of incorporation energy means that incorporation is energetically favourable. All total electronic energies in eqn (1) are calculated using the same basis set and exchange-correlation functional. The results of $E_{\text {inc }}\left(\mathrm{O}_{\mathrm{i}}\right)$ as discussed below correspond to the concentration of Ir $c=12.5 \%$ (L4) only.

\section{Calculation of thermoelectric properties}

CRYSTAL17 allows post-process DFT wavefunctions for evaluating the electron transport properties by solving the Boltzmann equation. Unlike other approaches implemented in popular codes such as BoltzTrap ${ }^{41}$ or BoltzWann, ${ }^{42}$ CRYSTAL17 performs analytical derivatives of the electronic bands. Several studies have shown that all these codes, despite their differences, yield similar results. ${ }^{43,44}$ At the core of the equations for the transport coefficients (such as Seebeck coefficient and electronic conductivity) is the transport distribution function, 

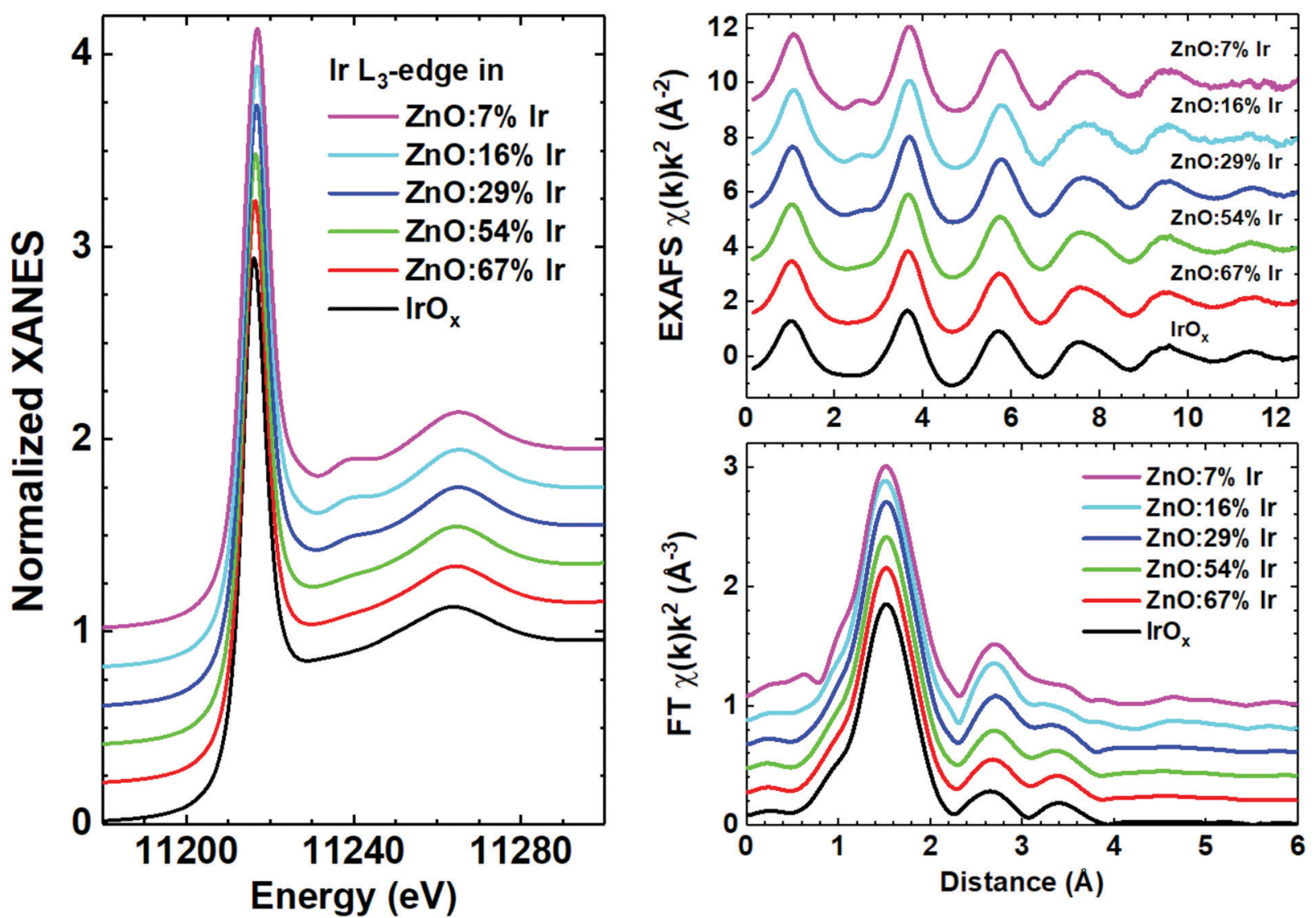

Fig. 1 Experimental Ir $\mathrm{L}_{3}$-edge XANES (left panel), EXAFS and their Fourier transforms (FT) (right panel) for mixed zinc-iridium oxide (ZnO:clr) and pure $\mathrm{rO}_{x}$ thin films.

cast here as the energy projected tensor:

$$
\Xi_{q r}(E)=\tau \sum_{k} \frac{1}{N_{k}} \frac{1}{V} \sum_{i, j} v_{i, q}(k) v_{j, r}(k) \delta\left(E-E_{i}(k)\right),
$$

where $N$ is the number of $k$-points used in sampling the reciprocal space, $v_{i, q}(k)$ is the velocity of the $i$ th $(j$ th) band calculated along the direction $q(r), \delta$ is an approximation to Dirac's delta function, and $\tau$ is the electronic relaxation time which is assumed to be not dependent on $k$ (constant relaxation time approximation). Relaxation time is temperature-dependent and cannot be obtained from first-principles calculations, and, therefore, must be either fitted or obtained experimentally. ${ }^{20,43}$ Throughout our calculations, we have used $\tau=10 \mathrm{fs}$, which is a conservative estimate for a system leaning towards conductivity. Values of $\tau$ for $\mathrm{ZnO}$, calculated from mobility data found in the literature, range from 17 to 57.9 fs for carrier concentrations $c a$. $\sim 10^{16} \mathrm{~cm}^{-3} \cdot{ }^{45,46}$

By integrating the conductivity distributions written with tensors of eqn (2), it is possible to obtain conductivity tensors, for instance, the electrical conductivity $\sigma$ :

$$
\sigma_{q r}(T ; \mu)=e^{2} \int \mathrm{d} E\left(-\frac{\partial f_{0}}{\partial E}\right) \Xi_{q r}(E),
$$

where $\mu$ is the chemical potential or Fermi level, $E$ is the energy, $f_{0}$ is the Fermi-Dirac distribution, and $T$ is the temperature.
Thermoelectric coefficient $\sigma S$, where the Seebeck coefficient $S$ is cast as:

$$
[\sigma S]_{q r}(T ; \mu)=\frac{e}{T} \int \mathrm{d} E\left(-\frac{\partial f_{0}}{\partial E}\right)(E-\mu) \Xi_{q r}(E) .
$$

For convenience, we use the Fermi level $\mu_{\mathrm{F}}=\mu-E_{\mathrm{VBM}}$ for the analysis of the main results, where $E_{\mathrm{VBM}}$ is the valence band maximum. The transport coefficients were calculated in CRYSTAL with the Fermi level step (parameter to MURANGE) equal to $0.1 \mathrm{eV}$ and the energy step (parameter to TDFRANGE) of $0.05 \mathrm{eV}$ for the supercell $\mathrm{L} 4(c=12.50 \%)$. Notice that the same parameters should be chosen with caution for the supercell L48 ( $c=1.04 \%$ ). Our careful treatment of these parameters for L48 suggested both the Fermi level step and the energy step should equal $0.05 \mathrm{eV}$.

\section{Results and discussion}

\section{Structural properties of synthesized samples}

Careful examination of the experimental EXAFS spectra and their FTs (Fig. 1) suggests that the local environment around iridium atoms is quite disordered, being typical for nanocrystalline or amorphous $\mathrm{IrO}_{x}$ films. ${ }^{47}$ Indeed, reliable structural contributions are present in FTs up to about $4 \AA$ and consist of three peaks: the main peak at $1.5 \AA$ is due to the nearest oxygen atoms of the first 

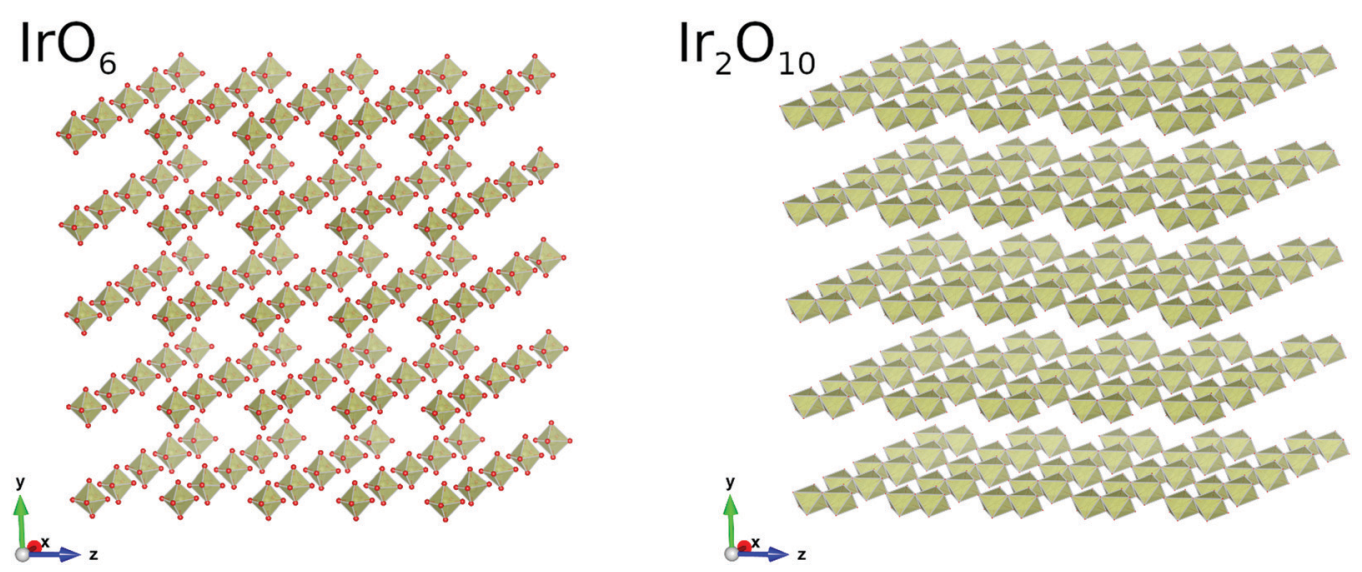

Fig. 2 Two $5 \times 5 \times 5$ supercell models used in the $\mathrm{RMC}$ simulations and composed of single $\mathrm{IrO}_{6}$ octahedra (left) and groups of two IrO ${ }_{6}$ octahedra joined by the edge (right).

coordination shell, while the origin of the next two peaks at 2.5 and 3.5 A should be clarified. Our previous experience suggests that in metal oxide thin films such peaks can be due to multiple-scattering (MS) effects within the first coordination shell of the metal atom ${ }^{48}$ with additional contributions originating from metal atoms located in the second coordination shell. ${ }^{49}$ Thus, the structural model required to describe the local environment of iridium should be cluster-like, i.e. containing a few atoms. Besides, the closeness of the experimental Ir $\mathrm{L}_{3}$-edge XANES and EXAFS spectra for pure $\mathrm{IrO}_{x}$ and Ir-doped $\mathrm{ZnO}$ thin films gives strong evidence for the similarity of their structures. The Ir $\mathrm{L}_{3}$-edge XANES is dominated by the white line at $\sim 11217 \mathrm{eV}$ due to the dipole allowed transition $2 \mathrm{p}_{3 / 2}(\mathrm{Ir}) \rightarrow$ $5 \mathrm{~d}(\mathrm{Ir})+2 \mathrm{p}(\mathrm{O}) .{ }^{50} \mathrm{~A}$ decrease of the iridium concentration leads to the appearance of the shoulder at $11240 \mathrm{eV}$, also visible in the EXAFS spectra at $2.5 \AA^{-1}$; it is due to the damped highfrequency contribution originating from peaks at $2-4 \AA$ in FTs. Thus, all samples can be roughly divided into two groups, having close XANES and EXAFS spectra; the first group with $c \leq 29 \%$ and the second group with $c \geq 54 \%$ and pure $\operatorname{IrO}_{x}$.

Crystalline $\mathrm{IrO}_{2}$ adopts the rutile-type structure (space group $\left.P 4_{2} / \mathrm{mnm}\right)$ with slightly distorted $(2 \times 1.96 \AA$ and $4 \times 2.00 \AA)$ octahedral coordination of iridium atoms by oxygens. ${ }^{51}$

The $\mathrm{IrO}_{6}$ octahedra are joined by edges along the $c$-axis direction forming chains, which are cross-linked by shared corners to four neighbouring chains. ${ }^{51}$ Therefore, we used different fragments of the rutile $\mathrm{IrO}_{2}$ structure to construct two structural models for RMC simulations. The first model included a single $\mathrm{IrO}_{6}$ octahedron, whereas the second model contained two $\mathrm{IrO}_{6}$ octahedra joined by the edge. In both cases, a $5 \times 5 \times 5$ supercell (a simulation box) was constructed (Fig. 2) and used in the RMC/EA simulations to get sufficient statistics from 125 independent structural units $\left(\operatorname{IrO}_{6}\right.$ or $\left.\operatorname{Ir}_{2} \mathrm{O}_{10}\right)$. Each iridium-oxygen unit was placed in the centre of the cell with a large enough size $(10 \AA \times 10 \AA \times 10 \AA)$ to exclude the influence of units located in the neighbouring cells on each other.

The details of the RMC/EA method were described previously. ${ }^{17,18}$ The number of simultaneously used atomic configurations in the EA method was 32 . At each iteration, the new atomic configuration was generated by randomly displacing all atoms in the simulation box with the maximally allowed shift of $0.4 \AA$ to get the best possible agreement between the Morlet wavelet transforms (WTs) of the experimental and calculated EXAFS spectra $\chi(k) k^{2}$. The calculations were performed in the $k$-space range from 1.5 to $11 \AA^{-1}$ and in the $R$-space range from 0.8 to $4.0 \AA$. No significant improvement in the residual was observed after 5000 iterations.

The configuration-averaged EXAFS spectra during each RMC/EA simulation were calculated using ab initio real-space multiple-scattering (MS) FEFF8.50L code ${ }^{52,53}$ including the MS effects up to the 4 th order. The scattering potential and partial phase shifts were calculated for each absorption edge only once within the muffin-tin (MT) approximation ${ }^{52,53}$ for the cluster with a radius of $5 \AA$, constructed from the rutile $\mathrm{IrO}_{2}$ structure and centred at the absorbing iridium atom. Small variations of the cluster potential due to atom displacements during the RMC/EA simulations were neglected. The complex exchangecorrelation Hedin-Lundqvist potential was used to account for the photoelectron inelastic losses within the one-plasmon approximation. ${ }^{54}$ The amplitude reduction factor $S_{0}{ }^{2}$ was included in the scattering amplitude, ${ }^{52,53}$ calculated by the FEFF code, and no additional correction of the EXAFS amplitude was performed.

The results of the RMC/EA simulations for two selected samples from each group are reported in Fig. 3 and 4 . As one can see, two simple structural models (Fig. 2) provide good agreement with the experimental data, reproducing contributions from all peaks observed in FTs. In ZnO:cIr samples with $c \leq 29 \%$, iridium atoms are octahedrally coordinated by six oxygens with $R(\mathrm{Ir}-\mathrm{O})=1.93 \pm 0.02 \AA$ and the mean square relative displacement (MSRD) $\sigma^{2}(\mathrm{Ir}-\mathrm{O})=0.0050 \pm 0.0005 \AA^{2}$. The group of peaks located at longer distances in FT is solely due to the MS effects within the $\mathrm{IrO}_{6}$ octahedron. In ZnO:cIr samples with $c \geq 54 \%$ and pure $\mathrm{IrO}_{x}$, iridium atoms are also octahedrally coordinated by six oxygens with slightly longer mean bonds $R(\operatorname{Ir}-\mathrm{O})=1.96 \pm 0.02 \AA$, having slightly larger MSRD $\sigma^{2}(\operatorname{Ir}-\mathrm{O})=0.0065 \pm 0.0005 \AA^{2}$. However, there is an additional iridium atom from the neighbouring octahedron located at $R(\mathrm{Ir}-\mathrm{Ir})=3.15 \pm 0.02 \AA$ with 

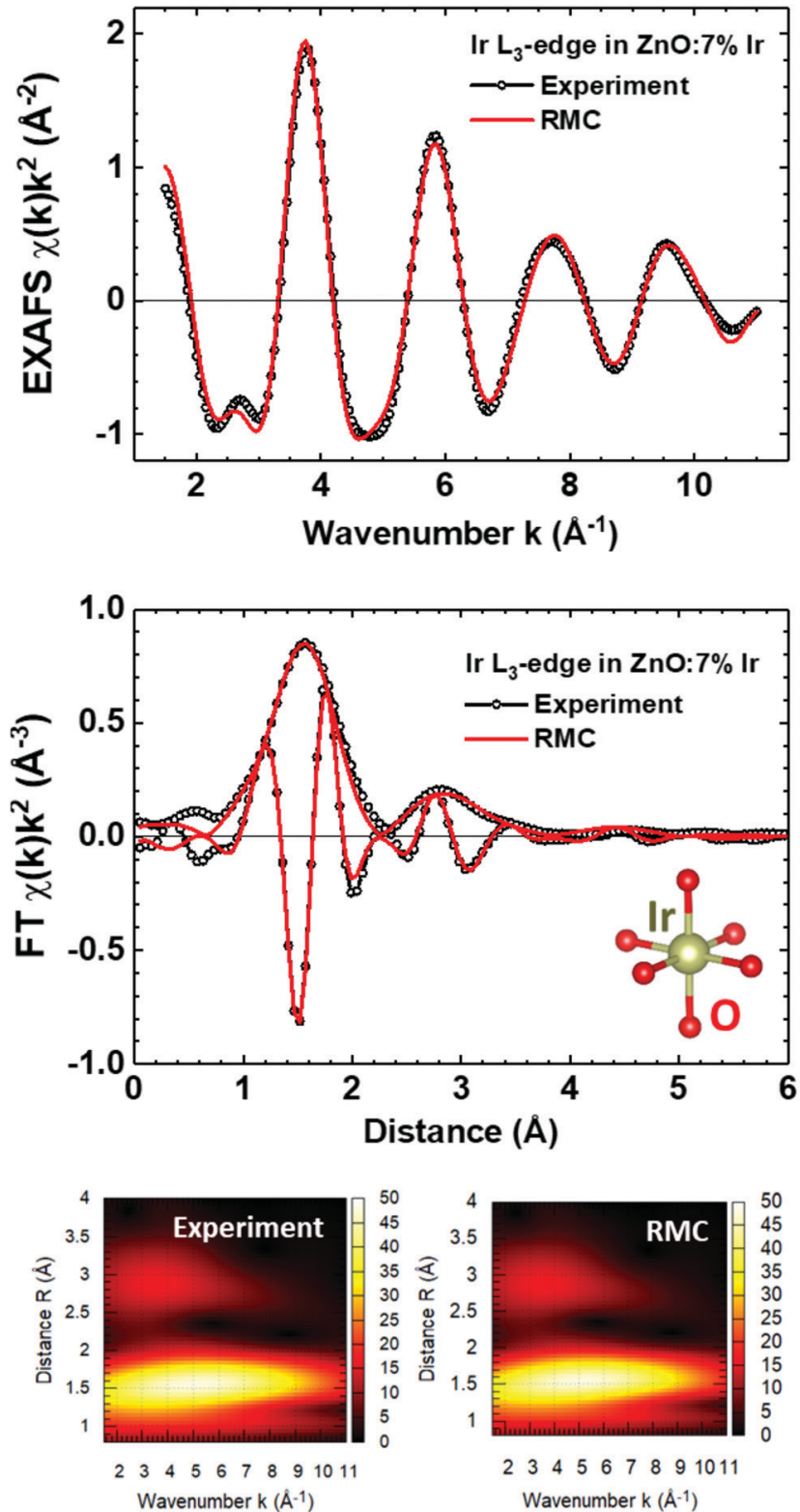

Fig. 3 Experimental and calculated by RMC Ir L3-edge EXAFS spectra $\gamma(k) k^{2}$ and their Fourier and Morlet wavelet transforms for the $\mathrm{ZnO}: 7 \% \mathrm{Ir}$ thin film.

$\operatorname{MSRD} \sigma^{2}(\mathrm{Ir}-\mathrm{Ir})=0.0056 \pm 0.0005 \AA^{2}$, whose EXAFS, together with that from the remaining 4 oxygen atoms, interferes with the MS contribution from the first shell, resulting in the two-peak structure in FT. Thus, at high Ir dopant concentration and in pure $\mathrm{IrO}_{x}$ films, structural groups of two $\mathrm{IrO}_{6}$ octahedra joined by the edge can be evidenced. These groups form chains in crystalline rutile-type $\mathrm{IrO}_{2} \cdot{ }^{51}$

DFT atomic structures of iridium-oxygen complexes in ZnO and parent compounds

We focus our discussion of the oxidation state $n$ of Ir in the $\operatorname{Ir}^{n} \mathrm{O}_{x}$ complex in $\mathrm{ZnO}$ on an analogy with "pure" reference compounds: $\mathrm{IrO}_{2}, \mathrm{Ir}_{2} \mathrm{O}_{3}$, and $\mathrm{ZnIr}_{2} \mathrm{O}_{4}$ (see the computational
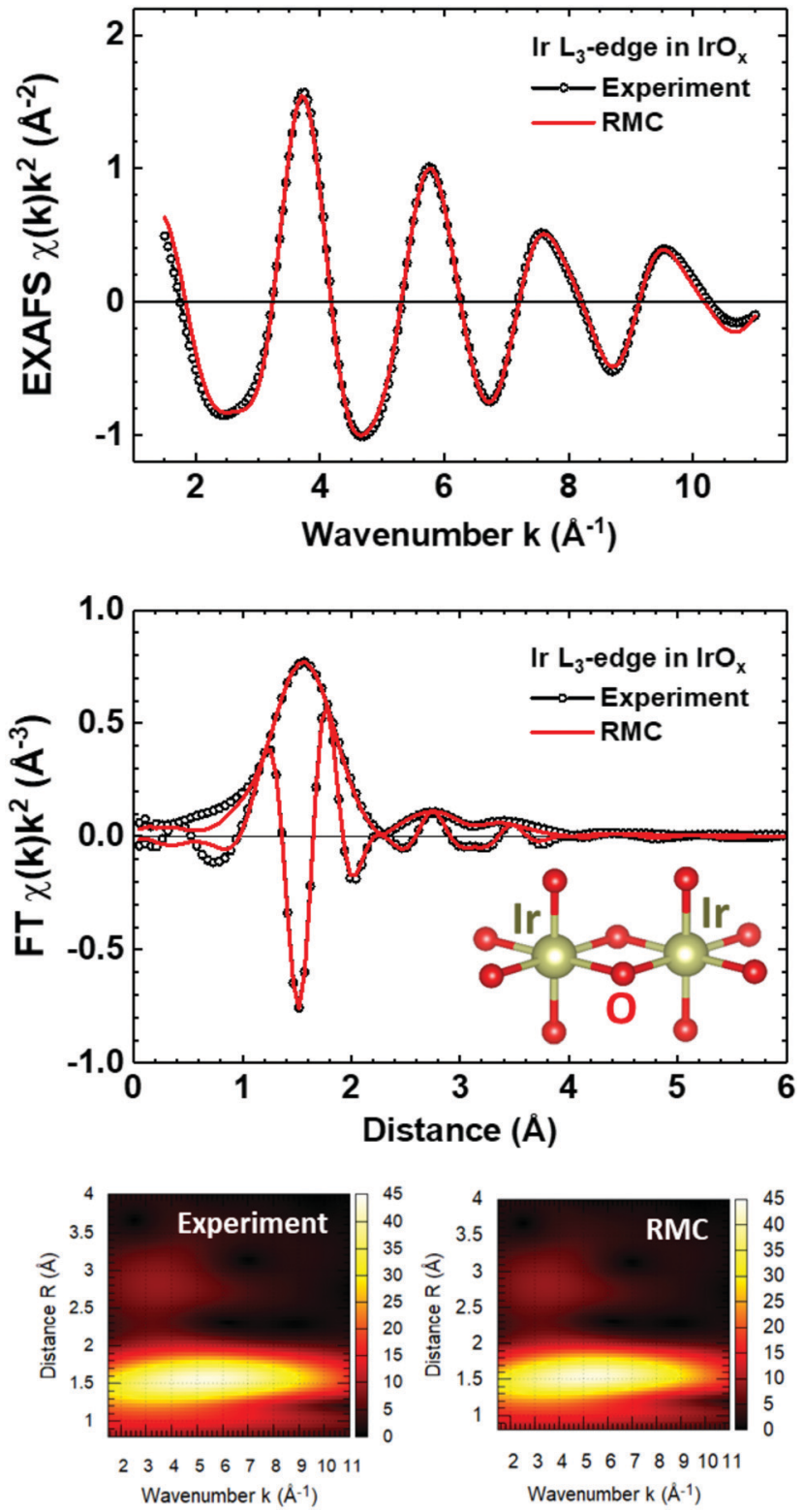

Fig. 4 Experimental and calculated by RMC Ir $\mathrm{L}_{3}$-edge EXAFS spectra $\chi(k) k^{2}$ and their Fourier and Morlet wavelet transforms for the pure $\operatorname{Ir} \mathrm{O}_{x}$ thin film.

details in Methods section). In either structure, Ir is six-fold coordinated, and in both $\operatorname{IrO}_{2}$ and $\operatorname{Ir}_{2} \mathrm{O}_{3}$ the six neighbouring

Table 1 Calculated bulk properties of $\mathrm{IrO}_{2}, \operatorname{Ir}_{2} \mathrm{O}_{3}$, and $\mathrm{ZnIr}_{2} \mathrm{O}_{4}$. a and $\mathrm{c}$ are the lattice parameters, $d_{\mid r-O}$ is the $\mid r-O$ interatomic distance, $q_{1 r}\left(\mu_{\mathrm{lr}}\right)$ and $q_{\mathrm{O}}\left(\mu_{\mathrm{O}}\right)$ are the effective atomic charges (magnetic moments) of Ir and $\mathrm{O}$, respectively, and $\Delta E$ is the bandgap value. An extended table (Table S1, ESI) with experimental data for comparison is present in the ESI

\begin{tabular}{|c|c|c|c|c|c|c|}
\hline Crystal & $d_{\mathrm{Ir}-\mathrm{O}}, \AA$ & $q_{\mathrm{Ir}}, e$ & $\mu_{\mathrm{Ir}}, \mu_{\mathrm{B}}$ & $q_{\mathrm{o}}, e$ & $\mu_{\mathrm{O}}, \mu_{\mathrm{B}}$ & $\Delta E, \mathrm{eV}$ \\
\hline $\mathrm{IrO}_{2}$ & $\begin{array}{l}\text { Short: } 1.942 \\
\text { Long: } 1.999\end{array}$ & 1.712 & 0.625 & -0.856 & 0.171 & Metal \\
\hline $\mathrm{Ir}_{2} \mathrm{O}_{3}$ & $\begin{array}{l}\text { Short: } 2.053 \\
\text { Long: } 2.085\end{array}$ & 1.241 & 0.000 & -0.827 & 0.000 & 3.39 \\
\hline $\mathrm{ZnIr}_{2} \mathrm{O}_{4}$ & 2.069 & 1.067 & 0.000 & -0.824 & 0.000 & 3.44 \\
\hline
\end{tabular}


oxygens are split into two groups (orbits) by symmetry, yielding long (axial) and short (azimuthal) Ir-O distances. The calculated lattice parameters of $\mathrm{IrO}_{2}$ and $\mathrm{ZnIr}_{2} \mathrm{O}_{4}$ are consistent with the experimental data (Table S1, ESI $\dagger$ ). Our results show several possible ways to distinguish $\mathrm{Ir}^{3+}$ from $\operatorname{Ir}^{4+}$ (Table 1). First, the magnetic moment $\left(\mu_{\mathrm{Ir}}\right)$ of Ir demonstrates that Ir in all these oxides is in the low-spin state with electron configurations $5 \mathrm{~d}^{5}$ $\left(n=4+, \mathrm{IrO}_{2}\right)$ and $5 \mathrm{~d}^{6}\left(n=3+, \mathrm{Ir}_{2} \mathrm{O}_{3}\right.$ and $\left.\mathrm{ZnIr}_{2} \mathrm{O}_{4}\right)$. Second, the effective atomic charge of $\operatorname{Ir}\left(q_{\mathrm{II}}\right)$ is quite different for $\mathrm{n}=3+$ and $4+$, which makes it a useful descriptor for comparing different $\operatorname{Ir}^{n} \mathrm{O}_{x}$ complexes. Thus, the larger $\left(q_{\mathrm{Ir}}\right)$ in $\operatorname{IrO}_{2}$ than in $\operatorname{Ir}_{2} \mathrm{O}_{3}$ and $\mathrm{ZnIr}_{2} \mathrm{O}_{4}$ is in accordance with a larger $n$ in the former. Third, the Ir-O distances are typically longer for $\mathrm{Ir}^{3+}$ than for $\mathrm{Ir}^{4+}$ as shown in Table 1.

The smaller ionic radius of $\operatorname{Ir}^{4+}$ leads to a smaller lattice constant in $\mathrm{IrO}_{2}$ and, therefore, stronger hybridization between the Ir and $\mathrm{O}$ electronic states. Interestingly, the bandgap $(\Delta E)$ values in $\mathrm{Ir}_{2} \mathrm{O}_{3}$ and $\mathrm{ZnIr}_{2} \mathrm{O}_{4}$ are quite close. It was discussed earlier that the use of the hybrid exchange-correlation functional is critical to reproduce the bandgap in $\mathrm{ZnIr}_{2} \mathrm{O}_{4} \cdot{ }^{13}$ The calculated $\Delta E$ for $\mathrm{ZnIr}_{2} \mathrm{O}_{4}$ in the present study is well comparable with the recently obtained experimental data in ref. 55 .

In Tables 2 and 3 we present basic properties of the most important configurations of $\operatorname{Ir}^{n} \mathrm{O}_{x}$ complexes, distinguished by the number of surrounding oxygens, incorporation energy (eqn (1)), oxidation state $\mathrm{n}$, and formation of peroxide fragments (or lack thereof). The main difference between the configurations is due to the number of oxygens surrounding Ir. We, thus, obtain the configurations with the number of surrounding oxygens ranging from 4 to 6 , whereas $n$ varies from $2+$ to $4+$. The obtained $n$-values are consistent with the oxidation states analysis for amorphous $\operatorname{IrO}_{x}$ powders. ${ }^{56}$ It was shown in that work that the average oxidation state of Ir is around 3.6 indicating the presence of $\mathrm{Ir}^{3+}$ and $\mathrm{Ir}^{4+}$ in the powders. The Ir oxidation state is $2+$ if the interstitial oxygens are absent $\left(\mathrm{Ir}^{2+} \mathrm{O}_{4}\right)$. In this case, $d_{\mathrm{Ir}-\mathrm{O}}, q_{\mathrm{Ir}}$ and $\mu_{\text {Ir }}$ are obviously different from the other oxidation states and configurations in Table 2.

In the case of the $\mathrm{Ir}^{3+} \mathrm{O}_{4}$ complex, Ir has four neighbors, too, and yet in this case the properties of Ir are not the same as in the $\operatorname{Ir}^{2+} \mathrm{O}_{4}$ case. In $\mathrm{Ir}^{3+} \mathrm{O}_{4}$, the value of $\mu_{\mathrm{Ir}}$ corresponds to $n=3+$ and an intermediate spin state (the formal value of $\mu_{\mathrm{Ir}}=2 \mu_{\mathrm{B}}$ ). However, $d_{\mathrm{Ir}-\mathrm{O}}$ in the $\mathrm{Ir}^{3+} \mathrm{O}_{4}$ complex differs from that in $\mathrm{Ir}_{2} \mathrm{O}_{3}$ and $\mathrm{ZnIr}_{2} \mathrm{O}_{4}$ (Table 1). It is smaller than in the parent oxides whereas $q_{\text {Ir }}$ in $\operatorname{Ir}^{3+} \mathrm{O}_{4}$ is close to the one of $\operatorname{Ir}$ in $\operatorname{Ir}_{2} \mathrm{O}_{3}$. The other two cases of $\mathrm{Ir}^{4+} \mathrm{O}_{5}$ and $\mathrm{Ir}^{4+} \mathrm{O}_{6}$ are characterized by small magnetic moments of Ir, consistent with the low spin
Table 3 Incorporation energy $\left(E_{\text {inc }}\left(O_{i}\right)\right)$ of interstitial oxygens $O_{i}$ (eqn (1)) in the different complexes (supercell L4, $c=12.5 \%$ ), $d_{O_{-} \mathrm{O}}$ is the O-O interatomic distance, and the local vibrational frequency $(\nu)$ of peroxide

\begin{tabular}{lllll}
\hline Complex & Peroxide & $d_{\mathrm{O}-\mathrm{O}}, \AA$ & $E_{\text {inc }}\left(\mathrm{O}_{\mathrm{i}}\right), \mathrm{eV}$ & $\nu, \mathrm{cm}^{-1}$ \\
\hline $\mathrm{Ir}^{3+} \mathrm{O}_{4}$ & Yes & 1.47 & -3.77 & 942 \\
$\mathrm{Ir}^{4+} \mathrm{O}_{5}$ & Yes & 1.54 & -4.37 & 810 \\
$\mathrm{Ir}^{4+} \mathrm{O}_{6}$ & No & - & -5.15 & -
\end{tabular}

configuration of the $5 \mathrm{~d}^{5}$ orbital. Such magnetic moments of Ir are very close to that in $\mathrm{IrO}_{2}$ (Table 1). In contrast to other complexes, the $\mathrm{O}_{\mathrm{i}}$ ions are Ir's nearest neighbors in the $\mathrm{Ir}^{4+} \mathrm{O}_{6}$ complex, and do not participate in the formation of peroxide defects.

The Ir-O distances are shorter in the complexes containing the $\mathrm{O}_{\mathrm{i}}$ ions than in the $\mathrm{Ir}^{2+} \mathrm{O}_{4}$ case and parent compounds, which is connected with a greater overlap of the orbitals and results in an increased oxidation state of Ir. The calculated average Ir-O bond length of the $\mathrm{Ir}^{4+} \mathrm{O}_{6}$ complex matches experimental data obtained with EXAFS $(1.94 \AA$ $v s .1 .96 \AA$ ̊). Interestingly, the larger supercell (L48) used for the $\operatorname{Ir}^{4+} \mathrm{O}_{6}$ complex did not demonstrate any changes in the basic properties (Table 1 ).

Table 3 indicates that the six-fold coordinated Ir is the energetically preferable state, as it is characterized by the lowest energy of incorporation. However, the $\mathrm{Ir}^{3+} \mathrm{O}_{4}$ and $\mathrm{Ir}^{4+} \mathrm{O}_{5}$ complexes contain the peroxide defects, formed by one $\mathrm{O}_{\mathrm{i}}$ ion and one host oxygen ion. The interatomic distances $\left(d_{\mathrm{O}-\mathrm{O}}\right)$ between these two oxygens are consistent with the values known for this type of defect (dumbbell) in other materials and $\mathrm{ZnO}$ from the DFT calculations. ${ }^{11,57-59}$

From the experimental viewpoint, the $\mathrm{O}-\mathrm{O}$ bond in $\mathrm{O}_{2}{ }^{2-}$ has been reported to have a length varied from 1.47 to $1.54 \AA$ for $\operatorname{Ir}\left(\mathrm{O}_{2}\right)$ complexes in organic compounds. ${ }^{60-62}$ The stretching vibration of the $\mathrm{O}-\mathrm{O}$ bond has been assigned $^{62}$ an IR absorption band at $\nu=833 \mathrm{~cm}^{-1}$. Likewise, $d_{\mathrm{O}-\mathrm{O}}$ of $1.47 \AA$ has been reported for a cubic zinc peroxide $\left(\mathrm{ZnO}_{2}\right){ }^{63}$ In the latter study, authors have observed a strong Raman peak centred at $835 \mathrm{~cm}^{-1}$, which they attribute to the $\mathrm{O}-\mathrm{O}$ stretching vibration through comparison with other published data. ${ }^{64,65}$ However, a larger calculated $d_{\mathrm{O}-\mathrm{O}}$ equal to $1.75 \AA$ for $\mathrm{ZnO}_{2}$ was associated with the experimentally measured $\nu$ of $748 \mathrm{~cm}^{-1}$ taken from the literature (see ref. 66 and references therein). Importantly, the present calculated $\nu$ 's of peroxide defect are only slightly larger than the measured one of $720 \mathrm{~cm}^{-1}$ for Ir-doped ZnO. ${ }^{10}$

\section{Analysis of the electronic structure}

Even without $\mathrm{O}_{\mathrm{i}}$ 's, Ir induces a non-zero spin on neighbouring oxygen ions in the $\mathrm{Ir}^{2+} \mathrm{O}_{4}$ complex. The magnetic moment of its

Table 2 Basic properties of $\operatorname{Ir}^{n} \mathrm{O}_{x}$ complexes. $d_{\mathrm{Ir}-\mathrm{O}}$ is the average $\mathrm{Ir}-\mathrm{O}$ interatomic distance, $q_{\mathrm{Ir}}$ is the effective atomic charge of $\mathrm{Ir}$, and $\mu_{\mathrm{Ir}}$ is the magnetic moment of Ir. Two supercell sizes were used for the $\operatorname{~Ir~}^{4+} \mathrm{O}_{6}$ complex for comparison, namely L4 and L48. Data obtained for the larger (L48) supercell is given in parentheses. Note that the $\mathrm{Zn}-\mathrm{O}$ distance in $\mathrm{ZnO}$ is $1.98 \AA$

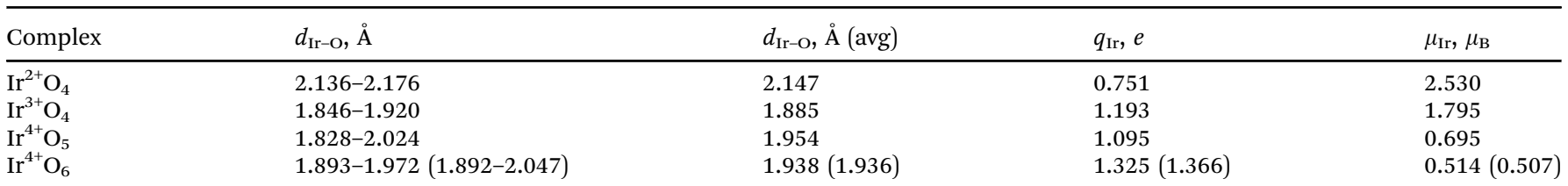



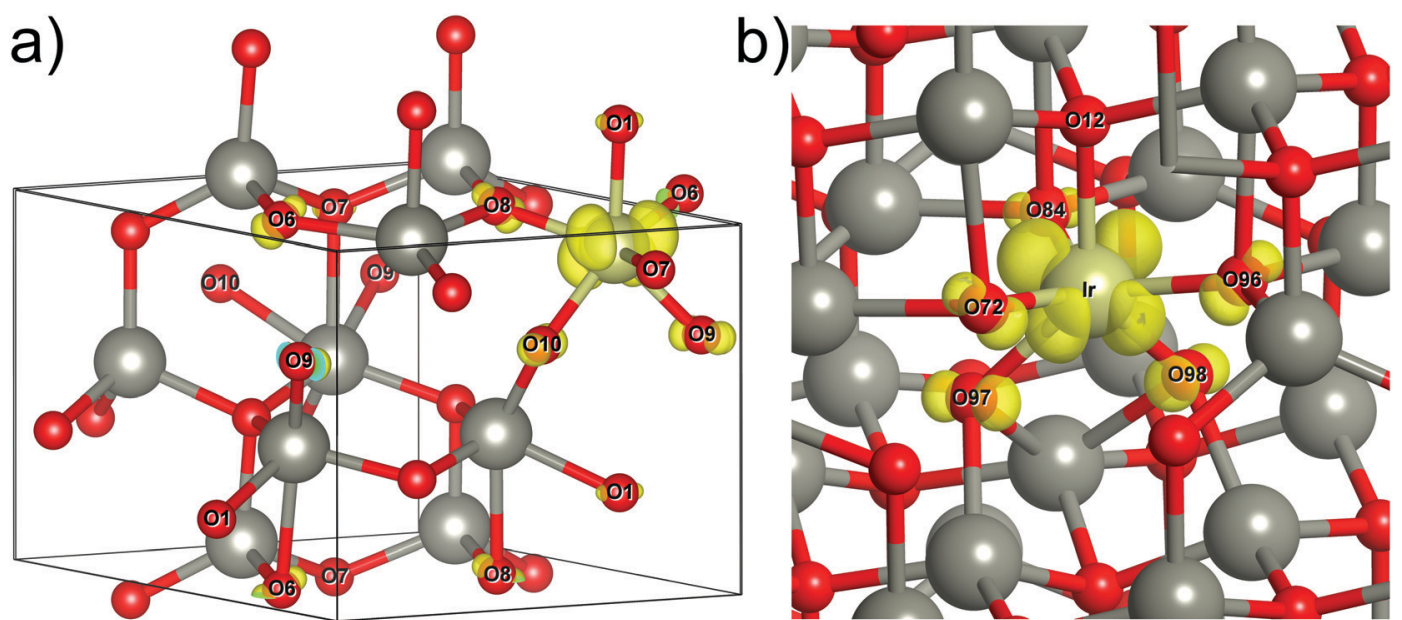

Fig. 5 The atomic structure and spin-density distribution in the small $L 4$ (a) and large $L 48$ (b) supercell for the $\mathrm{Ir}^{4+} \mathrm{O}_{6} \mathrm{Complex} \mathrm{Light}$ yellow spheres represent Ir atoms, gray $-\mathrm{Zn}$, and red - $\mathrm{O}$ atoms. Yellow clouds represent orbitals with unpaired electrons. Teal clouds are the same orbitals sectioned by the periodic boundary. The box marks the supercell boundaries. All named oxygen atoms are bound to Ir and have a nonzero spin.

$4 \mathrm{O}$ neighbours varies from $0.10-0.12 \mu_{\mathrm{B}}$. Such values of the magnetic moment are of the same order as those for the oxygens surrounding Ir in the complexes with $\mathrm{O}_{\mathrm{i}}$ 's. This is also well demonstrated by the spin density distribution shown in Fig. S1a-c (ESI $\dagger)$ and Fig. 5. The maximum spin density is localized on Ir whereas there is some part of the spin density on the nearest oxygen neighbours. A non-zero spin of oxygen ions surrounding Ir and the fact that these ions have a decreased charge (not shown) in comparison with other oxygen ions are very much in line with the same properties of $\mathrm{IrO}_{2}$ in contrast to $\mathrm{Ir}_{2} \mathrm{O}_{3}$ and $\mathrm{ZnIr}_{2} \mathrm{O}_{4}$ (Table 1). Ir is fully oxidized, and the electrons given to surrounding oxygens are distributed between them, including $\mathrm{O}_{\mathrm{i}}$ 's. This facilitates hole localization in Ir-doped ZnO. Interestingly, in the case of peroxide defect, the resultant fragment is asymmetric, with different magnetic moments of the two oxygens. Notice, however, that the magnetic moments of oxygens in $\mathrm{O}_{2}{ }^{2-}$ are more pronounced in the $\operatorname{Ir}^{4+} \mathrm{O}_{5}$ complex than in the $\operatorname{Ir}^{3+} \mathrm{O}_{4}$ one due to the smaller $\mathrm{O}-\mathrm{O}$ distance in the former case.

Analysis of the calculated density of states (DOS) for the $\mathrm{Ir}^{4+} \mathrm{O}_{6}$ complex (Fig. 6 and $7 \mathrm{c}$ ) revealed that the top of the valence band consists of Ir states and states of oxygens

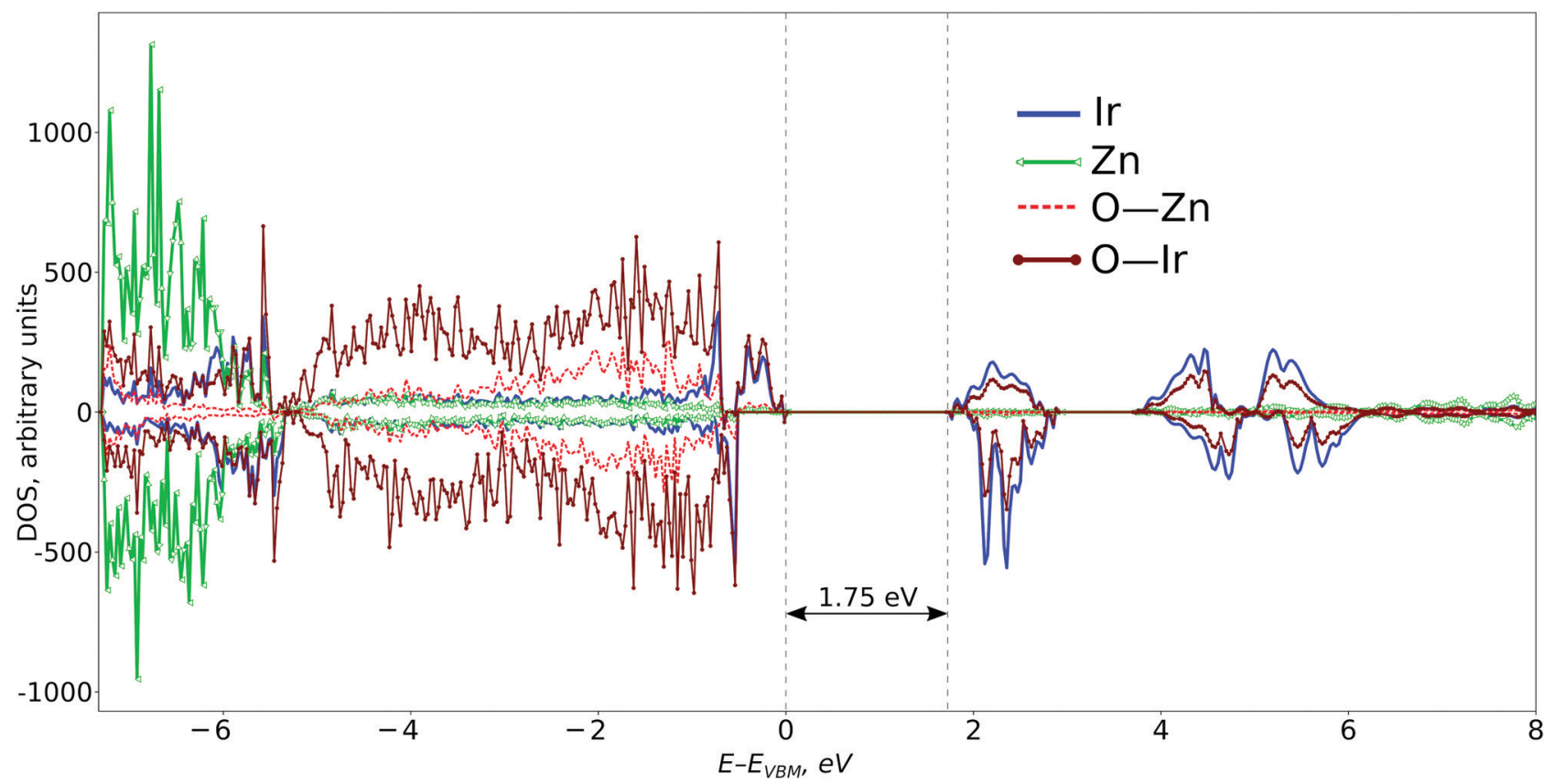

Fig. 6 Total and partial density of states (DOS) for $1 \mathrm{r}^{4+} \mathrm{O}_{6}$ calculated with the small supercell (L4). The O-Ir line describes the 6 oxygens surrounding Ir, whereas the $\mathrm{O}-\mathrm{Zn}$ line is for all the other oxygens in the supercell. The valence band maximum $\left(E_{\mathrm{VBM}}\right)$ is taken as zero. Negative DOS values correspond to the spin-down electrons. Signals of $\mathrm{Ir}, \mathrm{O}-\mathrm{Zn}$, and $\mathrm{O}-\mathrm{Ir}$ are scaled by factors of 10,3 , and 5 respectively. 


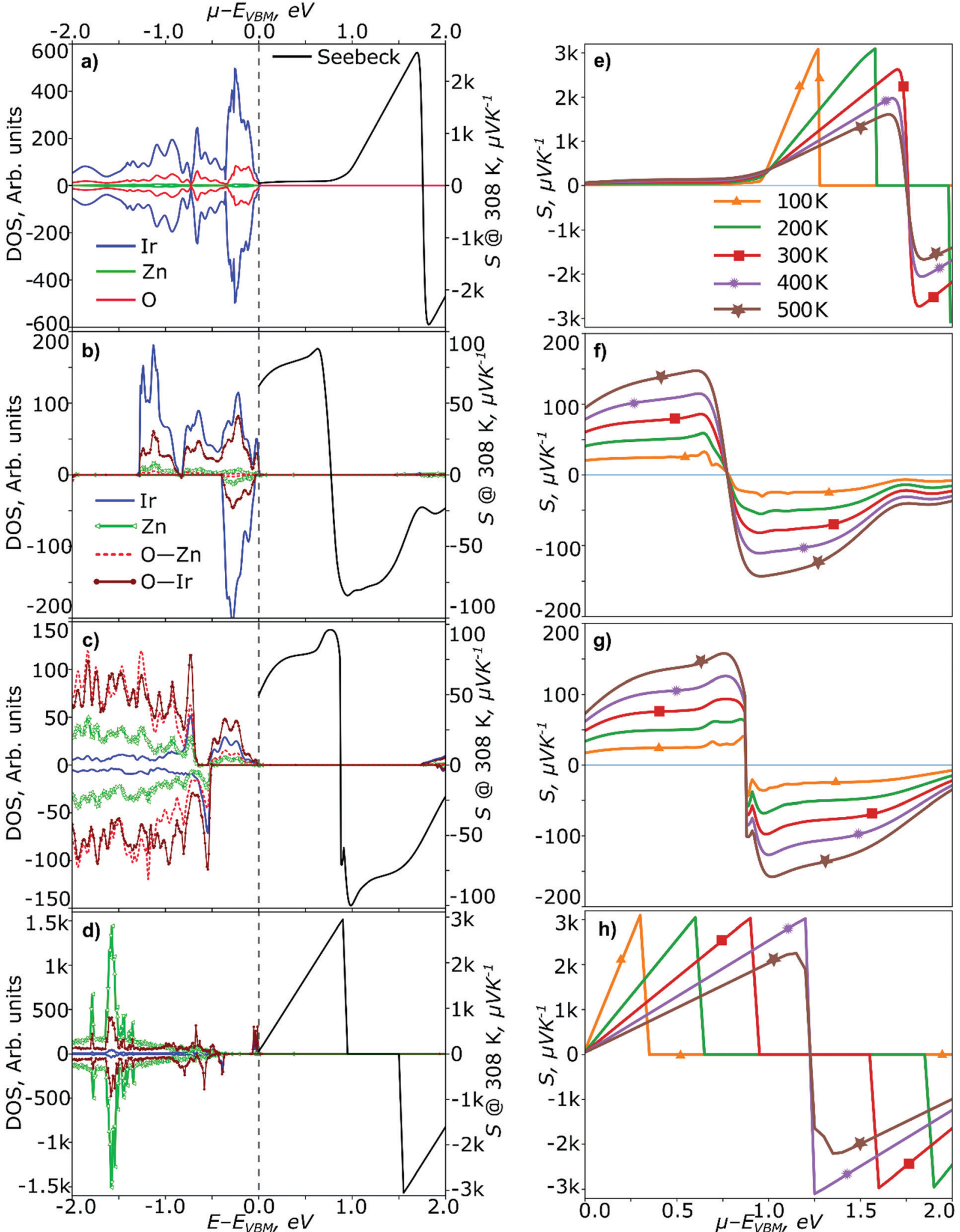

Fig. 7 Left panel: The partial DOS as a function of $E-E_{\mathrm{VBM}}$ (left-bottom axis) and Seebeck coefficient ( $\mathrm{S}$, black curve) at $T=308 \mathrm{~K}$ as a function of Fermi level $\mu_{\mathrm{F}}=\mu-E_{\mathrm{VBM}}$ (top-right axis). The valence band maximum $\left(E_{\mathrm{VBM}}\right)$ is taken as zero (grey dashed line). DOS lines are smoothed with a cubic spline. No scaling is applied. Right panel: $S\left(\mu_{\mathrm{F}}\right)$ for a range of temperatures. $\mathrm{ZnIr}_{2} \mathrm{O}_{4}$ : (a) and (e), $\mathrm{Ir}^{2+} \mathrm{O}_{4}$ : (b) and (f), $I \mathrm{r}^{4+} \mathrm{O}_{6}$ in $\mathrm{L} 4$ : (c) and (g), Ir ${ }^{4+} \mathrm{O}_{6}$ in $L 48$ : (d) and (h). The O-Ir line describes the oxygens surrounding $\mathrm{Ir}$, whereas the $\mathrm{O}-\mathrm{Zn}$ line is for all the other oxygens in the supercell. 
surrounding Ir (Ir-O band). It is the band of the width of $\sim 0.4 \mathrm{eV}$ (small supercell, L4). The states of the same oxygens are extended to deeper energies and hybridized with the states of other oxygens in the lattice (the total width of this band is around $5 \mathrm{eV}$ ). The $\mathrm{Zn}$ states contribute at even deeper energies. In the large supercell (L48, Fig. 7d), the Ir-O band is separated from the extended O-band which should have an impact on the calculated thermoelectric properties. The band gap in Ir-doped $\mathrm{ZnO}$ is between the occupied and unoccupied Ir-O bands and changes from 1.75 to $2.50 \mathrm{eV}$ for the small (L4, $c=12.50 \%)$ and large (L48, $c=1.04 \%)$ supercell.

Even though the overall characteristics in the calculated complexes are similar, there are still some differences to mention (Fig. S2, ESI $\dagger$ and Fig. 7b). The hybridization effect as discussed above is stronger in $\mathrm{Ir}^{3+} \mathrm{O}_{4}$ than in $\mathrm{Ir}^{4+} \mathrm{O}_{6}$. Essentially, the top of the valence band in $\mathrm{Ir}^{3+} \mathrm{O}_{4}$ is formed of Ir states and all oxygens in the lattice. In the case of the $\mathrm{Ir}^{4+} \mathrm{O}_{5}$ complex, the picture is similar with $\operatorname{Ir}^{4+} \mathrm{O}_{6}$, but the $\mathrm{Ir}-\mathrm{O}$ band is wider (almost $1 \mathrm{eV}$ ).

\section{Analysis of thermoelectric properties}

In the present analysis, we discuss the calculated thermoelectric properties, i.e. the Seebeck coefficient $(S)$ and electrical conductivity $(\sigma)$, for the $\mathrm{IrO}_{x}$ complexes in $\mathrm{ZnO}$ and reference systems: perfect $\mathrm{ZnO}, \mathrm{ZnIr}_{2} \mathrm{O}_{4}$ and $\mathrm{IrO}_{2}$. Thermoelectric properties are extremely sensitive to the electronic structure. Perfect $\mathrm{ZnO}$ is not expected to demonstrate good potential for the p-type conduction. We suggest that this property of $\mathrm{ZnO}$ is reflected in the steep increase of the calculated $S$ to unrealistically high values (see Fig. S2a, ESI $\dagger$ ) in the proximity of VBM.

In the calculations the exact Fermi level $\mu_{\mathrm{F}}$ is unknown but a comparison with the available experimental data could help with its identification. Therefore, $S$ and $\sigma$ dependence on $\mu_{\mathrm{F}}$ referenced at the VBM, i.e. $S\left(\mu_{\mathrm{F}}\right)$ and $\sigma\left(\mu_{\mathrm{F}}\right)$, lies at the heart of our analysis. Typically, such dependencies have two parts for positive and negative values of $S$ standing for holes and electrons, respectively. We, therefore, focus our analysis on the positive $S$-values only to estimate the potential of Ir-doped $\mathrm{ZnO}$ for the p-type conduction.

In Table 4 the calculated $\sigma$ - and $S$-values at fixed $\mu_{\mathrm{F}}$ are compared with the corresponding data found in the experimental literature and our previous experimental results. ${ }^{10}$ Notice that the experimental results differ by the sample preparation and treatment, leading to some scatter in data. Interestingly, it is almost the same value of $\mu_{\mathrm{F}}=\mu-E_{\mathrm{VBM}} \approx 0.7 \mathrm{eV}$ for all systems for both $S$ and $\sigma$ in Table 4 to find better correspondence with the experimental values and is, therefore, a good compromise for such a comparison.

The calculated $\sigma$-value for $\mathrm{ZnIr}_{2} \mathrm{O}_{4}$ and $\mathrm{IrO}_{2}$ agree very well with the experimental data. The cation vacancies and anti-sites are detrimental defects in spinels ${ }^{13,67}$ explaining, at least in part, the p-type conductivity. Thus, it should be reflected in the $S$-values as well. Indeed, we emphasize significant differences in the behaviour of $S\left(\mu_{\mathrm{F}}\right)$ for bulk $\mathrm{ZnIr}_{2} \mathrm{O}_{4}$ in a comparison with perfect ZnO. It has a well distinguished plateau in the range of $\mu_{\mathrm{F}}$ between 0 and $0.8 \mathrm{eV}$ (Fig. 7a) followed by a steep increase to very high values. A positive Seebeck coefficient of $92.3 \mu \mathrm{V} \mathrm{K}^{-1}$ at $\mu_{\mathrm{F}}=0.7 \mathrm{eV}$ is in agreement with the experimental values (Table 4).

The Ir-doped $\mathrm{ZnO}$ is characterized by a high sensitivity of thermoelectric properties to the electronic structure as well. All $\mathrm{IrO}_{x}$ complexes as discussed in the present study show different behaviour of $S\left(\mu_{\mathrm{F}}\right)$. However, we again emphasize the presence of a plateau and steep increase to very high values for some of the complexes. The positive Seebeck coefficient is in the range 60-80 and 55-90 $\mu \mathrm{V} \mathrm{K}^{-1}$ for the complex without the interstitial oxygens, $\left(\mathrm{Ir}^{2+} \mathrm{O}_{4}\right)$, and in the $\mathrm{Ir}^{4+} \mathrm{O}_{6}$ complex in the small supercell ( $c=12.5 \%$, L4), respectively, depending on $\mu_{\mathrm{F}}$ (in the range of $\mu_{\mathrm{F}}$ between 0 and $0.8 \mathrm{eV}$ ) at $308 \mathrm{~K}$. Neither the $\mathrm{Ir}^{2+} \mathrm{O}_{4}$ nor $\mathrm{Ir}^{4+} \mathrm{O}_{6}$ complex in the small supercell (L4) are characterized by the steep increase of $S\left(\mu_{\mathrm{F}}\right)$ as were found in perfect $\mathrm{ZnO}$ and $\mathrm{ZnIr}_{2} \mathrm{O}_{4}$. Here $S\left(\mu_{\mathrm{F}}\right)$ increases smoothly approaching the maximum value at $\mu_{\mathrm{F}} \sim 0.70-0.75 \mathrm{eV}$ (Fig. 7b and c). In contrast, the $\mathrm{Ir}^{4+} \mathrm{O}_{5}$ and $\mathrm{Ir}^{3+} \mathrm{O}_{4}$ complexes

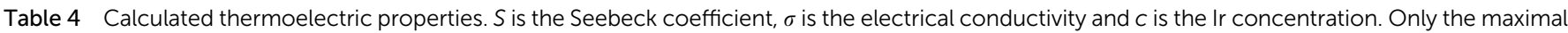

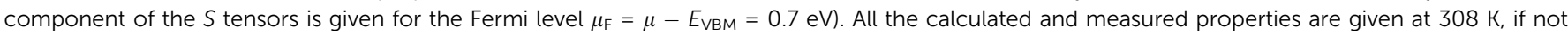
otherwise stated

\begin{tabular}{|c|c|c|c|c|}
\hline Compound & $S, \mu \mathrm{V} \mathrm{K} \mathrm{K}^{-1}$ & $S$ exp, $\mu \mathrm{V} \mathrm{K^{-1 }}$ & $\sigma, \Omega^{-1} \mathrm{~m}^{-1}$ & $\sigma \exp , \Omega^{-1} \mathrm{~m}^{-1}$ \\
\hline $\mathrm{ZnO}$ & 2510 & Non-conducting & $6.05 \times 10^{-8}$ & Non-conducting \\
\hline $\mathrm{ZnIr}_{2} \mathrm{O}_{4}$ & 92.3 & $53.9^{a} 68$ & $1.72 \times 10^{2}$ & $2.09 \times 10^{2}, 3.39 \times 10^{2 a} 68$ \\
\hline $\mathrm{IrO}_{2}$ & 63.9 & - & $1.32 \times 10^{6}$ & $\begin{array}{l}1.15-2.90 \times 10^{6} 69,70 \\
0.68-1.67 \times 10^{6} b 71 \\
2.94 \times 10^{6} c 71\end{array}$ \\
\hline $\mathrm{Ir}_{2} \mathrm{O}_{3}$ & 105 & - & $8.98 \times 10^{1}$ & - \\
\hline $\mathrm{Ir}^{2+} \mathrm{O}_{4}$ & 80.1 & $6.8^{d} 10$ & $2.57 \times 10^{2}$ & $47.6^{d} 10$ \\
\hline $\mathrm{Ir}^{3+} \mathrm{O}_{4}$ & 88.7 & & $3.20 \times 10^{1}$ & \\
\hline $\mathrm{Ir}^{4+} \mathrm{O}_{5}$ & 89.4 & & $4.13 \times 10^{1}$ & \\
\hline $\mathrm{Ir}^{4+} \mathrm{O}_{6}(c=12.5 \%, \mathrm{~L} 4)$ & 83.8 & & $1.62 \times 10^{2}$ & \\
\hline $\mathrm{Ir}^{4+} \mathrm{O}_{6}(c=1.04 \%, \mathrm{~L} 48)$ & 2335 & & $3.49 \times 10^{-8}$ & \\
\hline
\end{tabular}

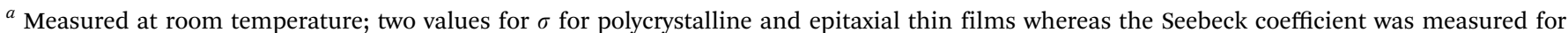

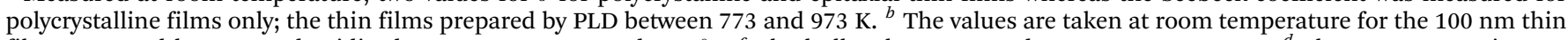

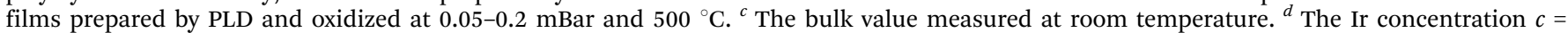
$16.4 \%$. 
(Fig. S2, ESI $\dagger$ ) show very similar behavior of $S\left(\mu_{\mathrm{F}}\right)$ with $\mathrm{ZnIr}_{2} \mathrm{O}_{4}$ and demonstrate much smaller changes for the $S$-values in the range of $\mu_{\mathrm{F}}$ between 0 and $0.8 \mathrm{eV}$. In Fig. S2b and c (ESI $\dagger$ ) it is demonstrated that the plateau in the range of $\mu_{\mathrm{F}}$ between 0 and $0.8 \mathrm{eV}$ is present and leads to the values of $S$ of the order of $\sim 89 \mu \mathrm{V} \mathrm{K}^{-1}$ (see also Table 4 ). The presence of a plateau and formation of $\mathrm{O}_{2}{ }^{2-}$ are, in our opinion, interconnected.

We do not expect perfect agreement for the absolute $S$-values between the experiment and simplified model in the calculation but rather present a qualitative picture explaining the p-type conduction in Ir-doped $\mathrm{ZnO}$. Also, we notice a significant decrease of $\sigma$ for the Ir concentration $c=1.04 \%\left(\operatorname{Ir}^{4+} \mathrm{O}_{6}, \mathrm{~L} 48\right)$. In this case there is again a steep increase of the calculated $\mathrm{S}$ to very high values (see Fig. 7d) in the proximity of VBM similar to perfect ZnO. In the complexes with the plateau, the steep increase is shifted to higher $\mu_{\mathrm{F}}$. At the values of $\mu_{\mathrm{F}}=0.8-1.9 \mathrm{eV}$ for $\mathrm{Ir}^{3+} \mathrm{O}_{4}$ and $0.8-1.6$ for $\mathrm{Ir}^{4+} \mathrm{O}_{5}$ the steep increase of $S$ is observed and transformation into the n-type conductor follows. Furthermore, $S\left(\mu_{\mathrm{F}}\right)$ is differently influenced by temperature $T$ in the two ranges of $\mu_{\mathrm{F}}, 0.0<\mu_{\mathrm{F}} \leq 0.8 \mathrm{eV}$ and $0.8<\mu_{\mathrm{F}} \leq$ 1.9(1.6) eV, in Fig. 7(f-h) and Fig. S2(d and e) (ESI $\dagger)$. At $\mu_{\mathrm{F}} \leq$ $0.8 \mathrm{eV}, S\left(\mu_{\mathrm{F}}\right)$ increases with $\mathrm{T}$, and an opposite behaviour is found in the range $0.8<\mu_{\mathrm{F}} \leq 1.9(1.6) \mathrm{eV}$ for the complexes with the steep increase. Qualitatively speaking, this picture is very close to what was observed for $\mathrm{ZnIr}_{2} \mathrm{O}_{4}$ as well (Fig. 7e).

\section{Conclusions}

We have successfully combined hybrid DFT calculations and Ir $\mathrm{L}_{3}$-edge XAS experiments to gain insight into the local atomic structure around iridium ions in Ir-doped $\mathrm{ZnO}$. The $\mathrm{ZnO}: \mathrm{cIr}$ ( $c=7 \%, 16 \%, 29 \%, 54 \%$ and $67 \%$ ) and $\mathrm{IrO}_{x}$ thin films of thickness 200-300 nm were deposited by reactive DC magnetron co-sputtering on polyimide tape substrates. The role of interstitial oxygens was emphasized in such experiments. Thus, the analysis of EXAFS spectra using the reverse Monte Carlo simulations revealed that iridium ions are predominantly octahedrally coordinated by oxygens. Consequently, several $\operatorname{IrO}_{x}(x=4-6)$ polyhedra (complexes) inside the wurtzite $\mathrm{ZnO}$ lattice were selected for the calculations of the atomic and electronic structure, vibrational and thermoelectric properties from the first principles.

The hybrid PBE0 exchange-correlation functional and Gaussian basis-set described very well the basic properties of $\mathrm{ZnO}, \mathrm{ZnIr}_{2} \mathrm{O}_{4}$, and $\mathrm{IrO}_{2}$ crystals, which justified further computational study of Ir-doped ZnO. The complexes $\left(\operatorname{Ir}^{n} \mathrm{O}_{x}\right)$ were distinguished by the oxidation state of $\operatorname{Ir}(n)$ and formation of peroxide defects, and as a consequence, by the different number of oxygens $(x)$ surrounding Ir ions. Their corresponding formulas were chosen as $\mathrm{Ir}^{2+} \mathrm{O}_{4}$ - the system without interstitial oxygens $\mathrm{O}_{\mathrm{i}}$ 's, $\mathrm{Ir}^{3+} \mathrm{O}_{4}$ - the first system with the interstitials and formation of peroxide defects $\mathrm{O}_{2}{ }^{2-}, \mathrm{Ir}^{4+} \mathrm{O}_{5}-$ the second system with the formation of peroxide defect, and lastly, $\operatorname{Ir}^{4+} \mathrm{O}_{6}$ the system with Ir ions which are octahedrally coordinated by oxygens. It is worth mentioning that the selected complexes containing two interstitial $\mathrm{O}_{\mathrm{i}}$ ions were found by a careful treatment of numerous spatial configurations with different total energies. However, we were able to choose the three most important ones and focus our study on the analysis of the relevant Seebeck coefficient, electrical conductivity and density of states for them. Moreover, the $\mathrm{Ir}^{4+} \mathrm{O}_{6}$ complex was calculated with two Ir concentrations, namely 12.50 and $1.04 \%$. We compared the calculated thermoelectric properties for the chosen complexes with those for the reference systems, i.e. perfect $\mathrm{ZnO}$, $\mathrm{ZnIr}_{2} \mathrm{O}_{4}$, and $\mathrm{IrO}_{2}$. Each calculated $\mathrm{IrO}_{x}$ complex demonstrated some differences in the calculated DOS. However, the main DOS feature of calculated complexes for the Ir concentration $12.5 \%$ is due to (1) the mixed Ir-O band contributing to the VBM, (2) the states of oxygens surrounding Ir and their extension and hybridization with the other oxygens states in the lattice, and (3) as a consequence, the predicted positive Seebeck coefficient and electrical conductivity for the Fermi level $\mu_{\mathrm{F}}$ (referenced at the VBM) lying in the range $0 \leq \mu_{\mathrm{F}} \leq 0.8 \mathrm{eV}$. In this $\mu_{\mathrm{F}}$-range the calculated Seebeck coefficients are close for the four calculated complexes including the one without $\mathrm{O}_{\mathrm{i}}$ 's. In contrast, the calculation of smaller Ir concentration (1.04\%) for the $\operatorname{Ir}^{4+} \mathrm{O}_{6}$ complex revealed the Seebeck coefficient behaviour similar with the hypothetical perfect $\mathrm{ZnO}$ which is reflected in its steep increase in the proximity of VBM. It can be explained by a separate $\mathrm{Ir}-\mathrm{O}$ band characterized by much weaker hybridization effect with the host oxygens and smaller width in a comparison with the larger concentration $\mathbf{1 2 . 5 \%}$. Such differences between the Ir concentrations should explain the sign change in the Seebeck coefficient behaviour observed experimentally in ref. 10 . Lastly, the calculated local vibrational frequencies of $\mathrm{O}_{2}{ }^{2-}$ peroxides entering two complexes, $\mathrm{Ir}^{3+} \mathrm{O}_{4}$ and $\mathrm{Ir}^{4+} \mathrm{O}_{5}$, are close to those in the Raman measurements in ref. 10. The complexes with the formation of peroxide defects, i.e. $\operatorname{Ir}^{3+} \mathrm{O}_{4}\left(\operatorname{Ir}^{4+} \mathrm{O}_{5}\right)$, also have the steep increase of Seebeck coefficient in the range $0.8<\mu_{\mathrm{F}} \leq 1.9(1.6)$ eV similar to $\mathrm{ZnIr}_{2} \mathrm{O}_{4}$.

\section{Author contributions}

A. C.: investigation, formal analysis, writing - original draft, visualization. D. G.: methodology, writing - review \& editing. N. V. S.: project administration, supervision. E. A. K.: project administration, supervision. A. Z.: investigation, M. Z.: investigation. A. K.: investigation, formal analysis, writing - review \& editing, visualization. A. A.: investigation. J. P.: funding acquisition.

\section{Conflicts of interest}

There are no conflicts to declare.

\section{Acknowledgements}

We greatly acknowledge the financial support via the ERAF Project No. 1.1.1.1/18/A/073. Calculations have been performed under the Project HPC-EUROPA3 (INFRAIA-2016-1-730897), 
with the support of the EC Research Innovation Action under the H2020 Programme. A. C. gratefully acknowledges the technical support received from KTH-PDC. Institute of Solid State Physics, University of Latvia as the Center of Excellence has received funding from the European Union's Horizon 2020 Framework Programme H2020-WIDESPREAD-01-2016-2017TeamingPhase2 under grant agreement No. 739508, project CAMART $^{2}$.

\section{Notes and references}

1 P. Novák, T. Kozák, P. Šutta, M. Kolega and O. Bláhová, Phys. Status Solidi A, 2018, 215, 1700951.

2 P. Novák, J. Očenášek, T. Kozák and J. Savková, Thin Solid Films, 2018, 660, 471-476.

3 J. Rezek, P. Novák, J. Houška, A. D. Pajdarová and T. Kozák, Thin Solid Films, 2019, 679, 35-41.

4 D. C. Look, B. Claflin, Y. I. Alivov and S. J. Park, Phys. Status Solidi A, 2004, 201, 2203-2212.

5 A. Janotti and C. G. Van de Walle, Rep. Prog. Phys., 2009, 72, 126501.

6 D. Mora-Fonz and A. L. Shluger, Phys. Rev. B, 2019, 99, 014202.

7 A. V. Uklein, V. V. Multian, G. M. Kuz'micheva, R. P. Linnik, V. V. Lisnyak, A. I. Popov and V. Ya. Gayvoronsky, Opt. Mater., 2018, 84, 738-747.

8 S. Lany, J. Osorio-Guillén and A. Zunger, Phys. Rev. B: Condens. Matter Mater. Phys., 2007, 75, 241203.

9 A. Kuzmin and J. Chaboy, IUCrJ, 2014, 1, 571-589.

10 M. Zubkins, R. Kalendarev, J. Gabrusenoks, A. Plaude, A. Zitolo, A. Anspoks, K. Pudzs, K. Vilnis, A. Azens and J. Purans, Thin Solid Films, 2017, 636, 694-701.

11 P. Erhart, A. Klein and K. Albe, Phys. Rev. B: Condens. Matter Mater. Phys., 2005, 72, 085213.

12 D. Muñoz Ramo and P. D. Bristowe, J. Phys.: Condens. Matter, 2016, 28, 345502.

13 D. M. Ramo and P. D. Bristowe, J. Chem. Phys., 2014, 141, 084704.

14 D. Muñoz Ramo and P. D. Bristowe, Thin Solid Films, 2014, 555, 112-116.

15 S. Belin, V. Briois, A. Traverse, M. Idir, T. Moreno and M. Ribbens, Phys. Scr., 2005, 980.

16 A. Kalinko, XAESA, https://github.com/aklnk/xaesa, 2020.

17 J. Timoshenko, A. Kuzmin and J. Purans, Comput. Phys. Commun., 2012, 183, 1237-1245.

18 J. Timoshenko, A. Kuzmin and J. Purans, J. Phys.: Condens. Matter, 2014, 26, 055401.

19 R. Dovesi, A. Erba, R. Orlando, C. M. Zicovich-Wilson, B. Civalleri, L. Maschio, M. Rérat, S. Casassa, J. Baima, S. Salustro and B. Kirtman, WIREs Comput. Mol. Sci., 2018, 8, e1360.

20 R. Dovesi, V. R. Saunders, C. Roetti, R. Orlando, C. M. Zicovich-Wilson, F. Pascale, B. Civalleri, K. Doll, N. M. Harrison, I. J. Bush, P. D'Arco, M. Llunell, M. Causà, Y. Noël, L. Maschio, A. Erba, M. Rerat and
S. Casassa, CRYSTAL17 User's Manual, University of Torino, Torino, 2017.

21 F. Pascale, C. M. Zicovich-Wilson, F. López Gejo, B. Civalleri, R. Orlando and R. Dovesi, J. Comput. Chem., 2004, 25, 888-897.

22 C. M. Zicovich-Wilson, F. Pascale, C. Roetti, V. R. Saunders, R. Orlando and R. Dovesi, J. Comput. Chem., 2004, 25, 1873-1881.

23 R. A. Evarestov, Quantum chemistry of solids: LCAO treatment of crystals and nanostructures, Springer, Berlin, New York, 2nd edn, 2012.

24 IUPAC Compendium of Chemical Terminology: Gold Book, ed. M. Nič, J. Jirát, B. Košata, A. Jenkins and A. McNaught, IUPAC, Research Triagle Park, NC, 2.1.0., 2009.

25 M. Peuckert, Surf. Sci., 1984, 144, 451-464.

26 M. Hara, K. Asami, K. Hashimoto and T. Masumoto, Electrochim. Acta, 1983, 28, 1073-1081.

27 W.-H. Chung, D.-S. Tsai, L.-J. Fan, Y.-W. Yang and Y.-S. Huang, Surf. Sci., 2012, 606, 1965-1971.

28 S. Kan, S. Takemoto, K. Kaneko, I. Takahashi, M. Sugimoto, T. Shinohe and S. Fujita, Appl. Phys. Lett., 2018, 113, 212104.

29 S. Kan, S. Takemoto, K. Kaneko, T. Shinohe and S. Fujita, 2018 IEEE CPMT Symposium Japan (ICSJ), IEEE, Kyoto, 2018, pp. 95-98.

30 P. J. Hay and W. R. Wadt, J. Chem. Phys., 1985, 82, 299-310. 31 A. W. Ehlers, M. Böhme, S. Dapprich, A. Gobbi, A. Höllwarth, V. Jonas, K. F. Köhler, R. Stegmann, A. Veldkamp and G. Frenking, Chem. Phys. Lett., 1993, 208, 111-114.

32 B. P. Pritchard, D. Altarawy, B. Didier, T. D. Gibson and T. L. Windus, J. Chem. Inf. Model., 2019, 59, 4814-4820.

33 Y. Ping, G. Galli and W. A. Goddard, J. Phys. Chem. C, 2015, 119, 11570-11577.

34 D. Gryaznov, E. Blokhin, A. Sorokine, E. A. Kotomin, R. A. Evarestov, A. Bussmann-Holder and J. Maier, J. Phys. Chem. C, 2013, 117, 13776-13784.

35 R. A. Evarestov, A. I. Panin, A. V. Bandura and M. V. Losev, J. Phys.: Conf. Ser., 2008, 117, 012015.

36 C. Adamo and V. Barone, J. Chem. Phys., 1999, 110, 6158-6170.

37 C. M. Bertoni, G. Cappellini, F. Finocchi, P. Monachesi, G. Chiarotti and P. Chiaradia, 7.3.3 II-VI compound surfaces: Datasheet from Landolt-Börnstein - Group III Condensed Matter, "Physics of Solid Surfaces" in SpringerMaterials, Springer-Verlag, Berlin Heidelberg, 2015, vol. 45A.

38 F. Oba, M. Choi, A. Togo, A. Seko and I. Tanaka, J. Phys.: Condens. Matter, 2010, 22, 384211.

39 H. J. Monkhorst and J. D. Pack, Phys. Rev. B: Solid State, 1976, 13, 5188-5192.

40 R. W. Grimes and C. R. A. Catlow, Philos. Trans. R. Soc., A, 1991, 335, 609-634.

41 G. K. H. Madsen and D. J. Singh, Comput. Phys. Commun., 2006, 175, 67-71.

42 G. Pizzi, D. Volja, B. Kozinsky, M. Fornari and N. Marzari, Comput. Phys. Commun., 2014, 185, 422-429. 
43 G. Sansone, A. Ferretti and L. Maschio, J. Chem. Phys., 2017, 147, 114101.

44 J. Linnera, G. Sansone, L. Maschio and A. J. Karttunen, J. Phys. Chem. C, 2018, 122, 15180-15189.

45 Ü. Özgür, Ya. I. Alivov, C. Liu, A. Teke, M. A. Reshchikov, S. Doğan, V. Avrutin, S.-J. Cho and H. Morkoç, J. Appl. Phys., 2005, 98, 041301.

46 S. Jantrasee, S. Pinitsoontorn and P. Moontragoon, J. Electron. Mater., 2014, 43, 1689-1696.

47 A. Kuzmin, R. Kalendarev, J. Purans and D. Pailharey, Advanced Optical Devices, Technologies, and Medical Applications, 2003, vol. 5123.

48 A. Kuzmin and R. Grisenti, Philos. Mag. B, 1994, 70, 1161-1176.

49 J. Gaidelene, R. Kalendarev, A. Kuzmin and J. Purans, Nucl. Instrum. Methods Phys. Res., Sect. A, 2004, 531, 321-326.

50 A. Balerna, E. Bernieri, E. Burattini, A. Kuzmin, A. Lusis, J. Purans and P. Cikmach, Nucl. Instrum. Methods Phys. Res., Sect. A, 1991, 308, 240-242.

51 A. A. Bolzan, C. Fong, B. J. Kennedy and C. J. Howard, Acta Crystallogr., Sect. B: Struct. Sci., 1997, 53, 373-380.

52 A. L. Ankudinov, B. Ravel, J. J. Rehr and S. D. Conradson, Phys. Rev. B: Condens. Matter Mater. Phys., 1998, 58, 7565-7576.

53 J. J. Rehr and R. C. Albers, Rev. Mod. Phys., 2000, 72, 621-654. 54 L. Hedin and B. I. Lundqvist, J. Phys. C, 1971, 4, 2064-2083. 55 M. J. Wahila, Z. W. Lebens-Higgins, A. J. Jackson, D. O. Scanlon, T.-L. Lee, J. Zhang, K. H. L. Zhang and L. F. J. Piper, Phys. Rev. B, 2019, 100, 085126.

56 V. Pfeifer, T. E. Jones, J. J. Velasco Vélez, C. Massué, R. Arrigo, D. Teschner, F. Girgsdies, M. Scherzer, M. T. Greiner, J. Allan, M. Hashagen, G. Weinberg, S. Piccinin, M. Hävecker, A. Knop-Gericke and R. Schlögl, Surf. Interface Anal., 2016, 48, 261-273.
57 R. A. Evarestov, A. Platonenko, D. Gryaznov, Y. F. Zhukovskii and E. A. Kotomin, Phys. Chem. Chem. Phys., 2017, 19, 25245-25251.

58 A. de Jamblinne de Meux, G. Pourtois, J. Genoe and P. Heremans, J. Appl. Phys., 2018, 123, 161513.

59 R. Thapa, S. Ghosh, S. Sinthika, E. Mathan Kumar and N. Park, J. Alloys Compd., 2015, 620, 156-163.

60 D. Bridget Williams, W. Kaminsky, J. M. Mayer and K. I. Goldberg, Chem. Commun., 2008, 4195.

61 M. G. Crestani, A. Steffen, A. M. Kenwright, A. S. Batsanov, J. A. K. Howard and T. B. Marder, Organometallics, 2009, 28, 2904-2914.

62 H. Baumgarth, T. Braun, B. Braun, R. Laubenstein and R. Herrmann, Eur. J. Inorg. Chem., 2015, 3157-3168.

63 A. Escobedo-Morales, R. Esparza, A. García-Ruiz, A. Aguilar, E. Rubio-Rosas and R. Pérez, J. Cryst. Growth, 2011, 316, 37-41.

64 N. Uekawa, N. Mochizuki, J. Kajiwara, F. Mori, Y. J. Wu and K. Kakegawa, Phys. Chem. Chem. Phys., 2003, 5, 929-934.

65 M. Sun, W. Hao, C. Wang and T. Wang, Chem. Phys. Lett., 2007, 443, 342-346.

66 G. L. Gutsev, B. K. Rao and P. Jena, J. Phys. Chem. A, 2000, 104, 11961-11971.

67 M. N. Amini, H. Dixit, R. Saniz, D. Lamoen and B. Partoens, Phys. Chem. Chem. Phys., 2014, 16, 2588.

68 M. Dekkers, G. Rijnders and D. H. A. Blank, Appl. Phys. Lett., 2007, 90, 021903.

69 Y. Liu, H. Masumoto and T. Goto, Mater. Trans., 2004, 45, 3023-3027.

70 W. D. Ryden, A. W. Lawson and C. C. Sartain, Phys. Rev. B: Solid State, 1970, 1, 1494-1500.

71 S. G. Bhat, A. M. Koshy, S. Pittala and P. S. A. Kumar, AIP Conf. Proc., 2017, 1859, 020007. 